Cite as: Olds AD, Olds, A. D., Albert, S., Maxwell, P. S., Pitt, K. A. and Connolly, R. M. (2013), Mangrove-reef connectivity promotes the effectiveness of marine reserves across the western Pacific. Global Ecology and Biogeography, 22: 1040-1049

\title{
Mangrove-reef connectivity promotes the effectiveness of marine reserves across the western Pacific
}

\author{
Andrew D. Olds ${ }^{* 1}$, Simon Albert ${ }^{2}$, Paul S. Maxwell ${ }^{1}$, Kylie A. Pitt ${ }^{1}$, Rod M. Connolly ${ }^{1}$ \\ 1. Australian Rivers Institute - Coast and Estuaries and School of Environment, Griffith \\ University, Gold Coast QLD 4222 \\ 2. Centre for Water Futures, University of Queensland, St Lucia, QLD 4072 \\ ${ }^{*}$ Corresponding author: Andrew Olds; Email: a.olds@griffith.edu.au \\ Phone: +61 75552 8983; Fax: +61 75552 8065; Other email addresses: \\ Article type: Research Paper \\ Running title: Connectivity and the effectiveness of Pacific marine reserves \\ Words: 295 in abstract, 4293 in main text, 6934 in manuscript. \\ References: 50 references. \\ Figures \& tables: 4 figures.
}

\section{ABSTRACT}

Aim To evaluate the potential of habitat connectivity to promote the effectiveness of marine reserves. We used heterogeneous reef seascapes as a model system to examine the potential interaction of reserves and mangrove-reef connectivity and compared the magnitude of these effects across the western Pacific Ocean.

Location The tropical and subtropical western Pacific, including the Solomon Islands, Great Barrier Reef, and Moreton Bay, Australia.

Methods We quantified fish densities on coral reefs (38 sites) and in mangrove forests (19 sites) across seven marine reserves and 12 unprotected control locations. Fish assemblages were in seascapes supporting either adjacent reefs and mangroves or isolated reefs. For each reserve-control comparison, we evaluated the potential interactive effects of habitat connectivity on species richness and densities of harvested species, functional groups, families and individual species. We then examined the influence of spatial variation in reserve attributes, seascape heterogeneity and latitude on the magnitude of reserve-connectivity effects.

Results Snappers (Lutjanidae) and rabbitfish (Siganidae) were more abundant on reserve reefs close to mangroves in all regions. These interactive effects also enhanced the abundance of sweetlip (Haemulidae), bream (Sparidae), harvested fish, herbivores and piscivores, and species richness, in two of the three regions examined. Spatial variation in the magnitude of reserve-connectivity effects was explained by differences among reserves in seascape variables (i.e. area of mangroves and reef, duration of mangrove inundation and distance to rivers), but not by reserve attributes (i.e. age, size, poaching) or latitude.

Main conclusions Habitat connectivity improved the effectiveness of reserves across the western Pacific Ocean. We recommend that heterogeneous landscapes with high habitat connectivity should be viewed as high priorities for conservation. By improving our understanding of connectivity, and through its explicit incorporation into conservation, we may have greater success in restoring biodiversity and the functioning of ecosystems.

\section{Keywords}

Australia, coral reef, Coral Triangle, fish, Great Barrier Reef, landscape ecology and biogeography, mangroves, marine reserve, Solomon Islands 


\section{INTRODUCTION}

We establish and manage reserves to restore biodiversity and maintain resilient, functioning ecosystems (Estes et al., 2011). Our success or failure will depend, in part, on our ability to incorporate difficult concepts, like connectivity, into strategies for ecosystem-based management (e.g. Massol et al., 2011) and spatial conservation planning (e.g. Foley et al., 2010). Connectivity is a fundamental component of many ecological paradigms (Sheaves, 2009), it is central to the distribution of all species, and is critical for maintaining ecosystem functions (Lindenmayer et al., 2008). By linking ecological processes and food webs across landscapes (Polis et al., 1997; Nyström \& Folke, 2001), it may also confer ecosystems with resilience (sensu Cumming, 2011), which is the capacity to absorb recurrent perturbations and regenerate without slowly degrading or changing state (Hughes et al., 2010). Consequently, understanding and enhancing connectivity is necessary for conservation (Hodgson et al., 2009). It provides the mechanism for reserves to sustain exploited fish populations beyond their borders (McCook et al., 2009), and is paramount to reversing human-mediated trophic cascades and their effects on ecosystem resilience (Estes et al., 2011). For this reason, connectivity is now integrated into strategies for conservation planning and environmental management, and recently, has been shown to improve the potential of reserves to enhance populations of exploited consumers (Olds et al., 2012a) and subsidise the supply of larvae to fished populations (Harrison et al., 2012).

Connectivity is governed by the dispersal capabilities of individual species and is a function of the area, quality and spatial arrangement of habitats (Hodgson et al., 2009). The term is frequently used to describe biological and physical linkages among habitats, landscapes and ecosystems (e.g. Lindenmayer et al., 2008; Sheaves, 2009; Beger et al., 2010a). This broad and flexible definition, together with the diversity and complexity of approaches for its quantification, makes connectivity difficult to conceptualise and evaluate (Calabrese \& Fagan, 2004). We focus on habitat connectivity, or the connectedness of patches of biogenic structure (in this case coral reef and mangroves) for particular mobile taxa (Lindenmayer \& Fischer, 2007). The effects of similar habitat connections can be seen in, and among, marine, freshwater and terrestrial ecosystems (Beger et al., 2010a). The benefits of this connectivity have, however, been degraded through habitat loss and alteration and species exploitation. Given the impending impacts of climate change, and the dearth of empirical evidence, a better understanding of the role for habitat connectivity in conservation is required (Estes et al., 2011).

Habitat connectivity has recently been shown to improve the effectiveness of marine reserves in the back-reef seascapes of the tropical Caribbean Sea (Nagelkerken et al., 2012) and subtropical Pacific Ocean (Olds et al., 2012a). 
These seascapes support a heterogeneous mix of coral reef, mangrove, seagrass and soft sediment habitats and are linked by an array of biological, physical, and chemical processes (Grober-Dunsmore et al., 2009). Fish, for example, migrate among habitats to utilize different resources (Nagelkerken, 2009), and populations and assemblages are influenced by the availability and spatial arrangement of habitats across the seascape (reviewed by Grober-Dunsmore et al., 2009; Bostrom et al., 2011; Berkström et al., 2012). These seascape effects can also drive a range of ecological processes and functions, namely: herbivory (e.g. Mumby \& Hastings, 2008), predation and predator-prey behaviour (e.g. Sheaves, 2009), food web structure (e.g. Heck et al., 2008) and ecological resilience (e.g. Olds et al., 2012c). Consequently, seascapes with well-connected habitats may support different assemblages and operate under different regimes of process and function than those that are isolated (sensu Nyström \& Folke, 2001).

We examined connectivity between mangroves and adjacent coral reefs, which are functionally linked by fish during tidal and diel movements and by ontogenetic migrations from juvenile nurseries to adult habitats (Nagelkerken, 2009; Sheaves, 2009). These connections operate across a range of scales, from 100s of metres for local feeding movements (e.g. Bostrom et al., 2011) to 10 s of kilometres for ontogenetic habitat shifts (Mumby, 2006). They can affect fish biomass in both habitats (Mumby et al., 2004), and the influence of marine reserves on fish populations (Olds et al., 2012a) and ecological resilience (Olds et al., 2012c). The importance of this habitat connectivity to the effectiveness of marine reserves was evaluated across three regions of the western Pacific Ocean: Roviana Lagoon (Solomon Islands), the Palm Islands (Great Barrier Reef, Australia), and Moreton Bay, Australia. These regions are separated by up to $20^{\circ}$ of latitude and vary in seascape heterogeneity, tidal regimes and reserve management styles. Each contains effective no-take marine reserves (e.g. Williamson et al., 2004; Aswani et al., 2007; Olds et al., 2012a) in heterogeneous seascapes with fish assemblages that are influenced by habitat connectivity and seascape ecology (e.g. Aswani \& Hamilton, 2004; Mellin et al., 2010; Olds et al., 2012b). The benefits of marine reserves (e.g. Edgar et al., 2011), and the importance of seascape ecology to fish assemblages (e.g. Mellin et al., 2010) have been demonstrated across similar regional scales, however, to date their potential interactive effects have only been examined at local scales. We tested the broader applicability of the hypothesis that mangrove-reef connectivity could promote the ability of reserves to enhance fish abundance, which had been established at a local scale (10s of km) (Olds et al., 2012a), by examining the interaction of these factors across 2,000 kilometres of the western Pacific Ocean. Given that mangroves provide a nursery for many juvenile reef fish, and therefore often harbour smaller individuals, a greater effect of marine reserves was anticipated on fish in adjacent reef habitat. Marine reserve 
effects vary with reserve age, context, latitude and the intensity of illegal fishing effort (e.g. Lester et al., 2009). The influence of habitat connectivity also differs with variation in seascape composition, heterogeneity, latitude and tidal range (e.g. Nagelkerken, 2009). Consequently, we also examined whether the magnitude of reserve-connectivity effects was explained by variation in seascape heterogeneity, reserve size and age, latitude and tidal regime. 


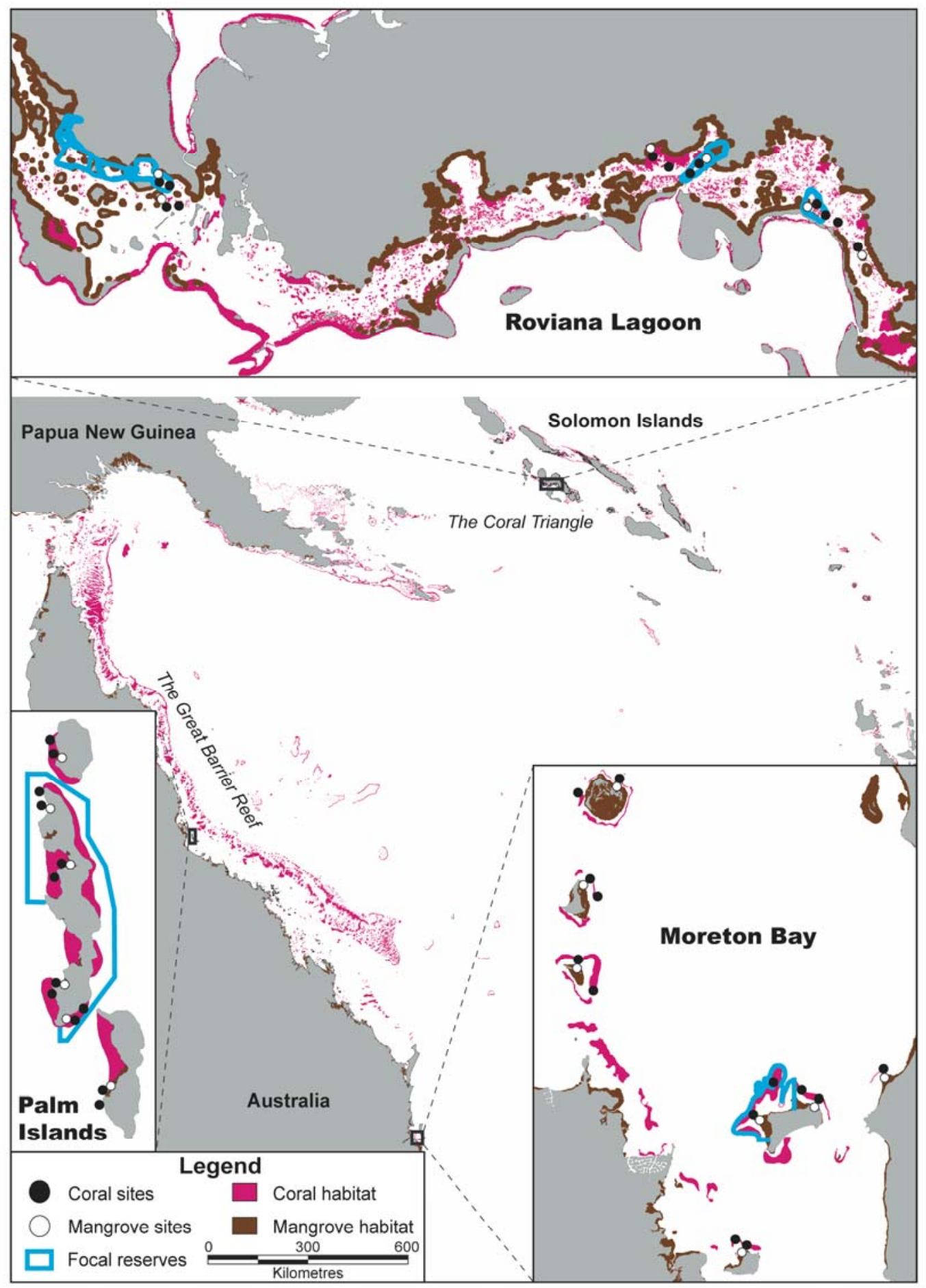

Figure 1 Mangrove and coral reef habitats of Roviana Lagoon (Solomon Islands), the Palm Islands (Great Barrier Reef) and Moreton Bay, Australia. Survey sites depicted as circles over mangrove and coral reef habitat. 


\section{MATERIAL AND METHODS \\ Seascapes studied}

We surveyed the fish of coral reef and mangrove habitats in marine reserves and unprotected control locations in Roviana Lagoon, the Palm Islands, and Moreton Bay (Fig. 1). These locations were selected to provide for variation along gradients of reserve size, seascape heterogeneity, mangrove inundation frequency and latitude. Roviana Lagoon ( $\left.8^{0} 17^{\prime} \mathrm{S}, 157^{\circ} 25^{\prime} \mathrm{E}\right)$ is located in the Solomon Islands and is part of the Coral Triangle ecoregion, which is recognized as the global centre of marine biodiversity with the highest priority for conservation (Veron et al., 2009). The lagoon is formed by raised offshore coral islands and supports heterogeneous tropical reef seascapes, which are managed in a network of small community-based marine reserves (established in 1999 and managed by the Roviana Conservation Foundation) (Aswani et al., 2007). The Palm Islands ( $18^{\circ} 35^{\prime} \mathrm{S}$, $146^{\circ} 30^{\prime} \mathrm{E}$ ) are located on the inner Great Barrier Reef (GBR), Australia, a World Heritage Area of globally significant biodiversity and the world's largest marine reserve network (McCook et al., 2010). The island group contains 10 granite-based continental islands, which are fringed by extensive shallow coral reefs and support stands of clear-water mangroves along their western shorelines (Williamson et al., 2004; Barnes et al., 2012). These tropical reefscapes are managed in the Great Barrier Reef Marine Park (established in 1987 and managed by the Great Barrier Reef Marine Park Authority)

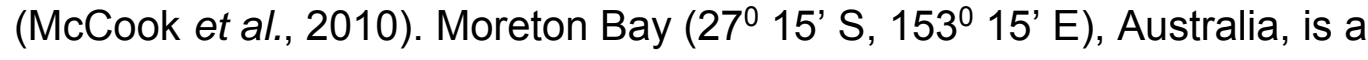
subtropical embayment south of the GBR that has been proposed as a potential refuge for tropical reef species threatened by climate change (Lybolt et al., 2011). It supports marginal fringing coral reefs, mangroves and seagrass in a heterogenous estuarine seascape, which is managed in the Moreton Bay Marine Park (established in 1997 and managed by the Queensland Parks and Wildlife Service) (Olds et al., 2012a). At the time of assessment, marine reserves had been closed to harvesting for: eight years in Roviana Lagoon, 24 years in the Palm Islands; and 13 years in Moreton Bay.

\section{Spatial analysis}

Field expeditions to Roviana Lagoon, the Palm Islands and Moreton Bay were undertaken between December 2009 and October 2011. We surveyed fish assemblages in three marine reserves and three unprotected control locations in Roviana Lagoon and the Palm Islands, and in one marine reserve and six unprotected locations in Moreton Bay. At the time of survey, there was only one effective marine reserve protecting back-reef seascapes in Moreton Bay. We adopted the most powerful experimental design possible in this circumstance, and utilised asymmetrical analyses to examine whether the single reserve location behaved differently to the average of multiple controls (see Olds et al., 2012a). At each location, we examined fish assemblages in 
mangroves close to reefs, on reefs close to mangroves, and on reefs distant from mangroves (Fig. 1). This design was adopted to capture the effects of tidal and ontogenetic connectivity between mangroves and reefs on fish assemblages and, therefore, necessitated spatial structure to the arrangement of sampling sites. Habitat connectivity was quantified as the edge-to-edge isolation distance between habitats from existing benthic habitat maps using ArcGIS (ESRI, Redlands, CA, USA) (sources: Great Barrier Reef Marine Park Authority, Queensland Department of Environment and Resource Management, Roviana Conservation Foundation and United Nations Environment Program). Isolation distances were scaled to the daily home ranges of species common to the coral reef and mangrove habitats of the western Pacific (sensu Grober-Dunsmore et al., 2009). Close reefs were within $250 \mathrm{~m}$ of mangroves, and isolated reefs were at least $500 \mathrm{~m}$ from mangroves. This scale encompassed daily home ranges of adult snappers (Lutjanidae), groupers (Serranidae), rabbitfish (Siganidae) and bream (Sparidae) (e.g. Sheaves, 1993; Zeller et al., 2003; Meynecke et al., 2008; Fox \& Bellwood, 2011). Ideally, home ranges of other species would also be included when selecting a spatial context, but movement data are lacking for other fish familles in the region. Studies of spatial patterns in ecology can only infer causality after first falsifying potential alternative explanations (Mumby et al., 2004), and we verified that reef fish distributions were not explained by covariation of habitat area, composition or benthic complexity and that illegal fishing effort did not vary with isolation or reserve status (see Appendix S1).

\section{Fish Assemblages}

Fish assemblages on coral reefs and at the mangrove fringe were surveyed using underwater visual census (following Olds et al., 2012a). Five replicate $50 \times 4 \mathrm{~m}$ belt transects were censused at each site; reefs were surveyed at low tide when mangroves were dry and not accessible to fish, and mangroves were surveyed at high tide when they were inundated and accessible.

Transects were standardised for depth, positioned in series parallel to the reef slope or mangrove fringe, and separated by a minimum of $50 \mathrm{~m}$. Each census consisted of a diver swimming the transect and recording the species, size and abundance of all fish greater than $5 \mathrm{~cm}$ total length (TL).

Fish assemblages occurring in reef and mangrove habitats were organised into the following groups: harvested species, functional groups (i.e. herbivores, piscivores, benthic invertebrate feeders), families, and densities of selected individual species. Species richness was also calculated as a surrogate for functional diversity (Micheli \& Halpern, 2005). Harvested species are most likely to respond to ecosystem protection; we used those listed as exploited in Australian fisheries (Rees et al., 2012), and those exploited in the subsistence fisheries of Roviana Lagoon (e.g. Aswani \& Hamilton, 2004). Herbivores are a crucial functional group underpinning reef resilience by grazing on algae (Hughes et al., 2010); herbivore density was calculated from 
the families Acanthuridae, Ephippidae, Kyphosidae, Pomacanthidae, Scaridae and Siganidae (following Choat et al., 2002). Piscivores are important in structuring marine food webs and influence trophic transfers among habitats (Sheaves, 2009); piscivore density was determined from species that commonly consume fish (following, Baker \& Sheaves, 2005). Roving benthic invertebrate feeders undertake tidal or diel migrations to forage in habitats adjacent to coral reefs and can provide important subsidies to reef food webs when they return (Heck et al., 2008); the density of benthic invertebrate feeders was calculated from the families Haemulidae, Holocentridae, Labridae, Lethrinidae, Mullidae and Nemipteridae. Harvested fish include species of herbivores, piscivores and benthic invertebrate feeders, whereas these trophic guilds are independent.

\section{Data Analysis}

Reserve and habitat connectivity effects were evaluated using a modified Control-Impact design. Analysis examined effects on fish variables through comparison of reserve and control locations in each region separately: three reserves and controls from Roviana Lagoon and the Palm Islands and one reserve and six controls from Moreton Bay. Fish density data were log transformed to produce homogenous variances and analysed with analysis of variance (ANOVA). We used three-factor ANOVAs for reef fish and two-factor analyses for mangrove fish data from Roviana Lagoon and the Palm Islands. The factors were: protection (a fixed orthogonal factor), location (a random orthogonal factor) and habitat connectivity (a fixed orthogonal factor used in reef analyses only). Asymmetrical ANOVA (Underwood, 1992) was conducted for Moreton Bay, to examine whether the single reserve location differed from the average of the six controls (see Olds et al., 2012a). We conducted twofactor ANOVAs for reef fish and one-factor analyses for mangrove fish. The factors were: location (an asymmetrical random orthogonal factor with only one reserve) and habitat connectivity (a fixed orthogonal factor used in reef analyses only). Post hoc Student-Newman-Keuls tests were used to differentiate significant means.

To determine if reserves and habitat connectivity influenced the composition of reef fish assemblages, data from each region were examined separately using permutational multivariate analysis of variance (PERMANOVA). Canonical analysis of principal coordinates (CAP) was used to visualise significant factors following PERMANOVA and to identify species that were primarily responsible for driving these differences (full description in Appendix S2).

The influence of marine reserves on fish abundance varies with reserve age and the intensity of illegal fishing effort (e.g. Lester et al., 2009). Similarly, the effects of habitat connectivity potentially also differ with variation in seascape composition, heterogeneity, latitude and tidal range (Nagelkerken, 2009). 
Thus we used general linear models (GLM) to examine the effect of these reserve and seascape variables on the magnitude of reserve-connectivity effects among the seven reserves surveyed. Magnitude of effect was expressed as the proportion of all reef fish species for which abundance was positively affected by a statistically significant interaction between reserve and habitat connectivity effects. Reserve variables included: reserve area, age and intensity of illegal fishing effort (refer Appendix S1). Seascape variables included: habitat area (proportion of each reserve containing mangroves and coral reef), duration of mangrove inundation (hours each day), latitude and the distance to rivers and oceanic passages. Analyses were conducted separately for each independent variable. We used an arcsine square root transformation on the index of reserve-connectivity effects (i.e. the proportion of all reef fish species affected) to meet the assumptions of homogeneity of variance for the GLM. 


\section{RESULTS}

\section{Habitat connectivity and reserve effects on fish assemblages}

Protection had the greatest effect on fish densities on reefs close to mangroves. Snappers (Lutjanidae) and rabbitfish (Siganidae) were more abundant on reserve reefs close to mangroves in all three regions (Fig. 2, Appendix S3). Harvested fish, herbivores and species richness followed the same trend at all locations, except one protected area in Roviana Lagoon (Fig. 2, Appendix S3). Sweetlip (Haemulidae) and piscivores were more abundant on reserve reefs close to mangroves in Roviana Lagoon and the Palm Islands (Fig. 2, Appendix S3). Piscivores were more abundant on reserve reefs in Moreton Bay, regardless of their isolation from mangroves (Fig. 2, Appendix S3). Bream (Sparidae) were also more abundant on reserve reefs close to mangroves in the Palm Islands and Moreton Bay, but were not recorded in Roviana Lagoon (Fig. 2, Appendix S3).

Protection also influenced fish densities in mangroves that were close to reefs. Piscivores were more abundant in reserve mangroves in all three regions (Fig. 2, Appendix S3). Snapper and sweetlip were more abundant in reserve mangroves in Roviana Lagoon and the Palm Islands (Fig. 2, Appendix S3); species richness also followed this trend. Bream were more abundant in reserve mangroves in the Palm Islands and Moreton Bay, but were not recorded in Roviana Lagoon (Fig. 2, Appendix S3). Harvested species were more abundant in protected mangroves in the Palm Islands; effects elsewhere varied among locations (Fig. 2, Appendix S3). There was no consistent effect of protection on the abundance of herbivores or rabbitfish in mangroves (Fig. 2, Appendix S3).

Habitat connectivity influenced the effects of marine reserves on the abundance of fourteen fish species, which utilized adjacent reefs and mangroves (Appendix S3). This included four snappers, three rabbitfish, two sweetlip, and two bream, which were largely responsible for observed patterns in family and functional group abundance. It also incorporated one hardyhead (Atherinidae), an emperor (Lethrinidae) and a parrotfish (Scaridae). The magnitude of these species-level effects, however, differed among regions with variation in species composition and abundance.

The effects of habitat connectivity on reef fish assemblages were influenced by an interaction with reserve status in Roviana Lagoon, the Palm Islands and Moreton Bay (Fig. 3, Appendix S2). These differences were driven by variation in the abundance of bream (Sparidae), rabbitfish (Siganidae), snappers (Lutjanidae) and sweetlip (Haemulidae), but the species responsible differed among regions (Fig. 3, Appendix S2). 
Cite as: Olds AD, Olds, A. D., Albert, S., Maxwell, P. S., Pitt, K. A. and Connolly, R. M. (2013), Mangrove-reef connectivity promotes the effectiveness of marine reserves across the western Pacific. Global Ecology and Biogeography, 22: 1040-1049

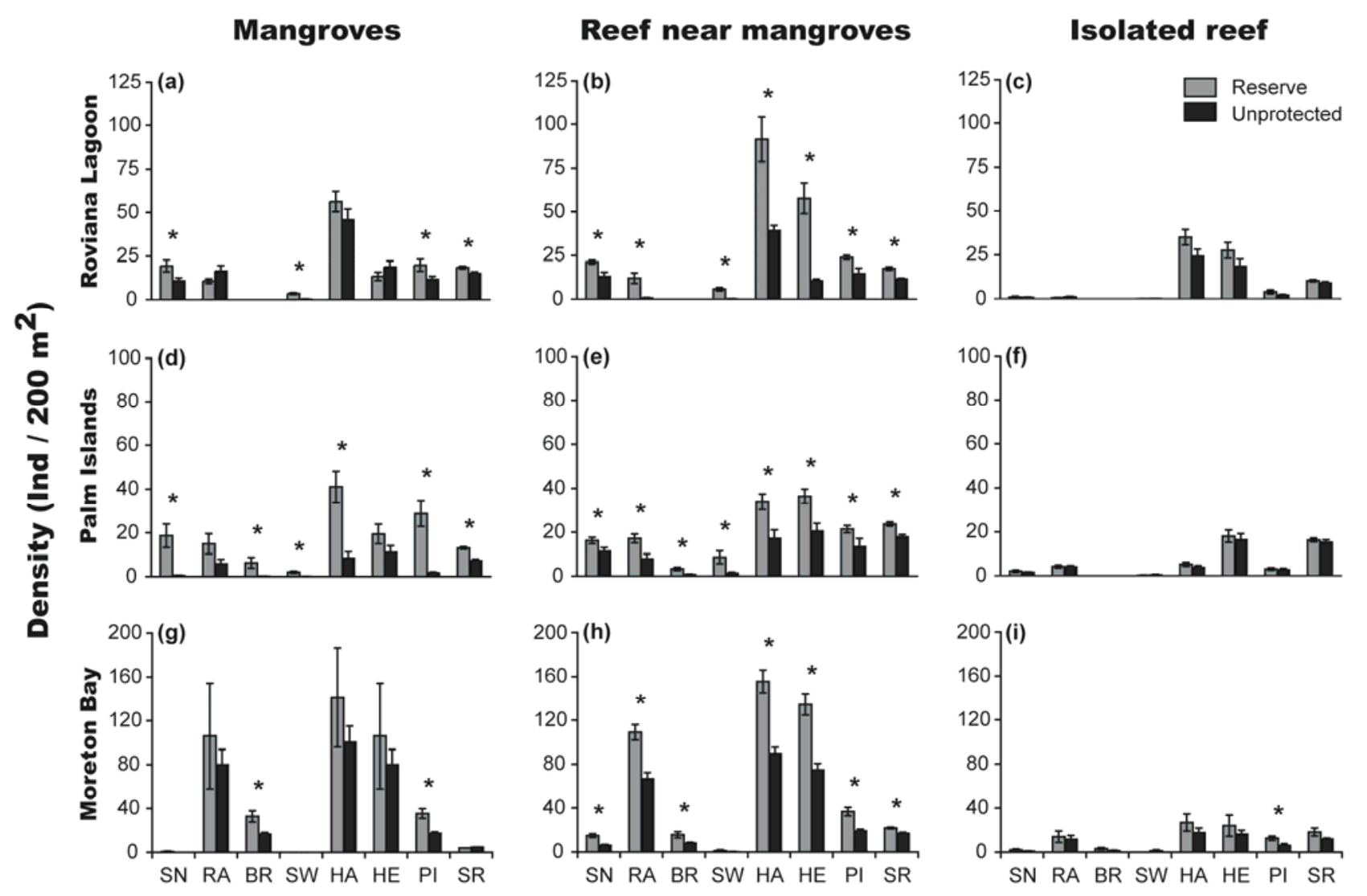

Figure 2 Density of snappers (Lutjanidae), rabbitfish (Siganidae), bream (Sparidae), sweetlip (Haemulidae), harvested fish, herbivores, piscivores and species richness in mangroves and on coral reefs (mean $\pm \mathrm{SE}$ ). SN, snappers; RA, rabbitfish; BR, bream; SW, sweetlip; HA, harvested fish; HE, herbivores; PI, piscivores; SR, species richness. * represent significant differences between reserve and unprotected locations (identified by SNK post hoc analyses). 

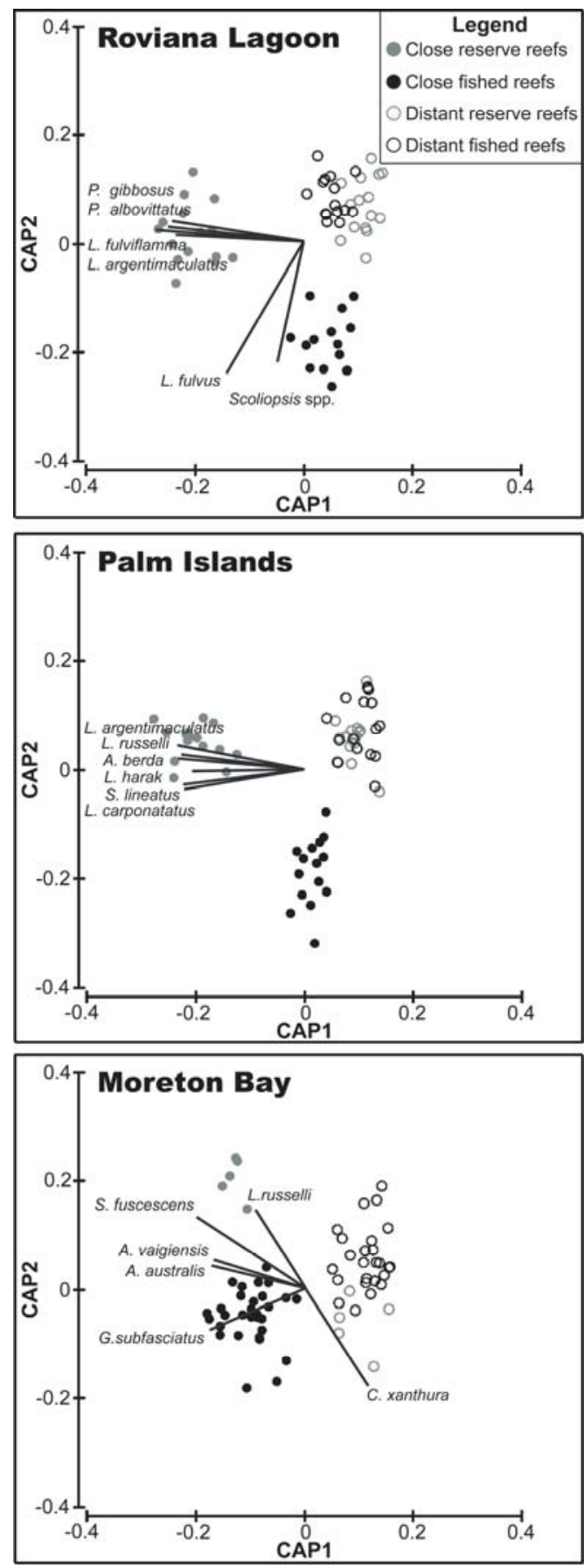

Figure 3 Constrained canonical analyses of principal coordinates (CAP) illustrating relationships among reef fish assemblages in Roviana Lagoon $\left(\delta^{2}=0.84, m=6, L O A=83.33 \%\right.$, $)$, the Palm Islands $\left(\delta^{2}=0.88, m=12, L O A=\right.$ $78.33 \%)$ and Moreton Bay $\left(\delta^{2}=0.89, m=10, L O A=92.31 \%\right)$. Ordinations based on modified Gower (Log 2) dissimilarities with Status (black versus grey circles) and Connectivity (shaded versus unshaded circles). Species correlations with the canonical axis are represented as vectors for species with Pearson $\mathrm{R}$ value greater than 0.6; e.g. Lutjanus argentimaculatus is positively correlated with protected sites near mangroves in Roviana Lagoon and the Palm Islands. 


\section{Spatial variation in the magnitude of reserve-connectivity effects}

Of the eight reserve and seascape variables examined in the GLMs, only the area of mangroves and reef $\left(r^{2}=0.80, p=0.041\right)$, mangrove inundation $\left(r^{2}=\right.$ $0.81, p=0.037)$ and distance to nearest river $\left(r^{2}=0.86, p=0.020\right)$ were correlated with the magnitude of reserve-connectivity effects (Fig. 4, Appendix S4). Non-linear, polynomial models for each of these three variables explained significant spatial variation in the magnitude of reserve-connectivity effects among reserves in Roviana Lagoon, the Palm Island group and Moreton Bay (Fig. 4, Appendix S4). The magnitude of reserve-connectivity effects increased with habitat area (i.e. proportion of each reserve containing mangroves and coral reef) and the duration of mangrove inundation (hours each day) and decreased with distance from the nearest river (Fig. 4). In contrast, the magnitude of reserve-connectivity effects was not correlated with spatial variation in reserve latitude, area or age, the distance to nearest oceanic passage, or the intensity of illegal fishing effort (Appendix S4). 


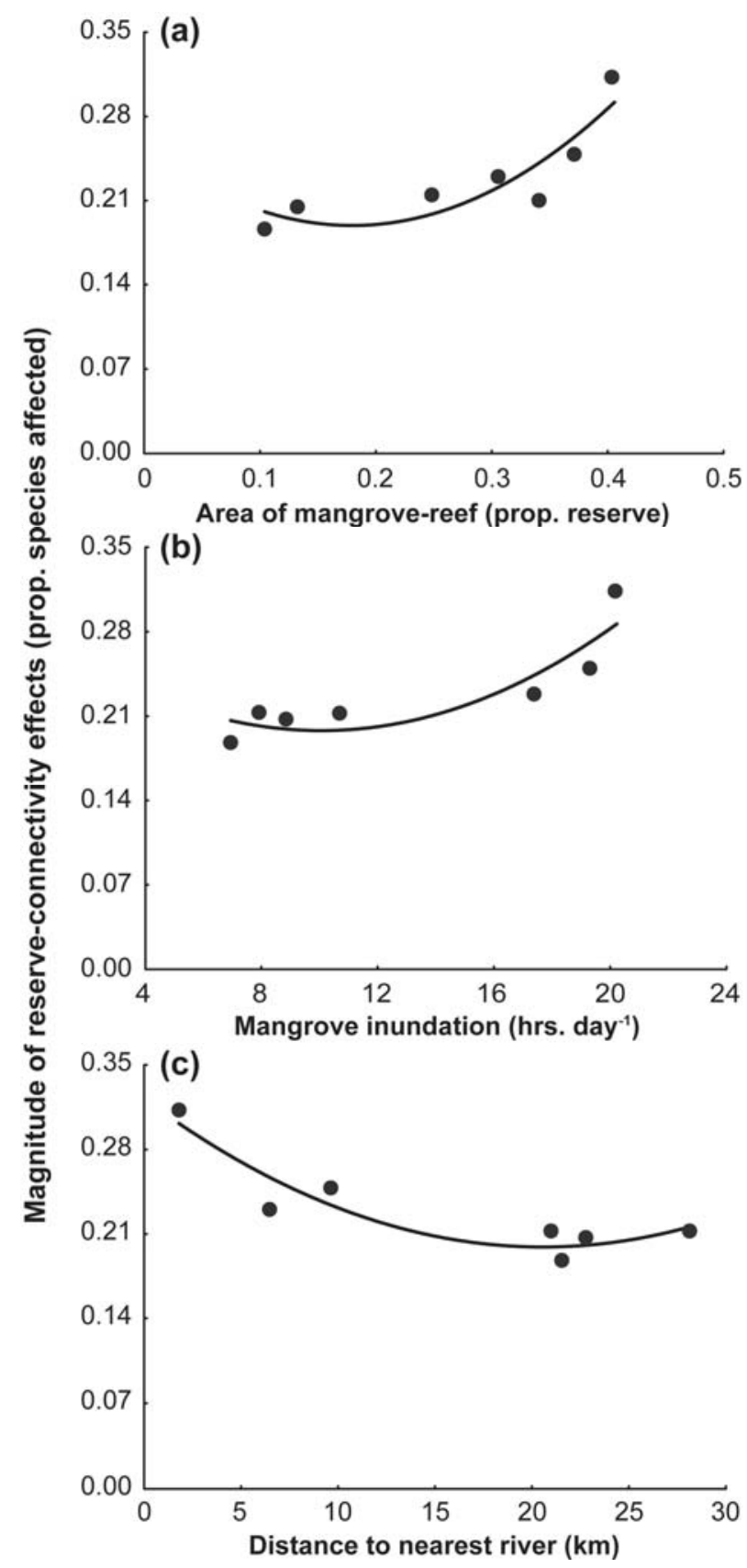

Figure 4 Relationships between the magnitude of reserve-connectivity effects (expressed as the proportion of reef fish species affected by a statistically significant interaction between reserve and connectivity effects) and: (a) area of mangrove and reef (i.e. proportion of each reserve containing mangroves and coral reef), (b) the duration of mangrove inundation (hours each day), and (c) the distance of reserves from the nearest river. Curves are lines of best fit from significant $(P<0.05)$ polynomial general linear models, as described in the text. 


\section{DISCUSSION}

Conservation actions are typically concerned with enhancing biodiversity and ecosystem resilience, and consequently, considerable research has focused on identifying important species, processes and landscape elements for conservation (Estes et al., 2011). Connectivity is paramount among these, and consequently, is now being integrated into strategies for ecosystembased management (e.g. Massol et al., 2011) and spatial conservation planning (e.g. Foley et al., 2010). This concept has been well researched in terrestrial ecosystems, but by comparison its value remains poorly understood for marine conservation and fisheries management (Lindenmayer et al., 2008; Sheaves, 2009; Estes et al., 2011). We demonstrate positive effects of habitat connectivity on the effectiveness of reserves across the western Pacific Ocean, and in doing so extend the findings of Olds et al. (2012a) from a local (10s of $\mathrm{km}$ ) to regional (over $2,000 \mathrm{~km}$ and $20^{\circ}$ of latitude) scale. Our results show that connectivity between reefs and mangroves (with a threshold at the $100-1,000 \mathrm{~m}$ scale) can improve the effectiveness of reserves, and increase the abundance of four fish families, harvested fish, herbivores and piscivores, and species richness on protected reefs. The broader implications of this result are, however, limited by the fact that we were unable to evaluate fish assemblages prior to reserve establishment. Prior data would be necessary to effectively control for natural spatial and temporal variability, but are commonly not available for studies of reserve effectiveness (Lester et al., 2009). Nevertheless, our results support greater incorporation of spatial ecology into ecosystem-based management (sensu Foley et al., 2010; Massol et al., 2011). It is important to recognise, however, that there can be many drawbacks to connectivity in reserve networks, including enhanced pathogen and invasive species exchange (Kellner \& Hastings, 2009), reduced spatial risk spreading (McCook et al., 2009), decreased ecological representation (Game et al., 2008) and, for reefs nearer to mangroves, increased proximity to sources of sediments, nutrients and detritus (Beger et al., 2010a). The decision to prioritise connectivity in conservation planning, therefore, creates a trade-off between these competing interests and other conservation targets (Hodgson et al., 2009; Beger et al., 2010b).

Our findings demonstrate that connectivity between reefs and mangroves can improve the effectiveness of marine reserves, but they also indicate that the magnitude of these reserve-connectivity effects can vary among different seascapes. By examining the potential drivers of this spatial variation (i.e. reserve and seascape influences) we determined that the relative magnitude of reserve-connectivity effects correlated with differences among reserves in the area of mangroves and reef, duration of mangrove inundation and distance to the nearest river. This result is not particularly surprising as these variables can affect the influence of habitat connectivity on coastal fish assemblages (e.g. Nagelkerken, 2009). It is noteworthy, however, that these 
seascape-level effects were more influential than other reserve-level attributes (i.e. age and intensity of illegal fishing effort), which also affect reserve performance (e.g. Lester et al., 2009). These results suggest that greater effects of mangrove-reef connectivity might be expected for reserves in heterogeneous inshore seascapes, which lie close to rivers, and experience high frequencies of mangrove inundation. Collectively, these variables influence the area and availability of both habitats, and consequently exert indirect effects on habitat connectivity. Inter-reef connectivity is, perhaps, more important to the composition of reef fish assemblages on offshore reefs (sensu Mellin et al., 2010), and the performance of reef reserve networks may similarly be enhanced by incorporating inter-reef connectivity (Beger et al., 2010b) and ontogenetic linkages with nursery habitats (Nagelkerken et al., 2012).

Mangroves and coral reefs are connected by the tidal, diel and ontogenetic migrations of a range of fish species (Nagelkerken, 2009; Sheaves, 2009). Mangroves are important juvenile habitats for many reef species, and consequently typically support smaller and younger individuals (Mumby et al., 2004; Barnes et al., 2012; Nagelkerken et al., 2012). The effects of mangrove to reef ontogenetic habitat shifts may be apparent in the results of this study, and emphasised by the greater influence of marine reserves on species on coral reefs than in mangroves. This is an interesting idea, for it suggests that we may need to reconsider how reserve effects are evaluated in nearshore coastal habitats. Indeed, the value of juvenile habitats is accepted to result from their importance for maintaining a high density, survival, growth and productivity of juveniles, which underpins the biomass of adults in offshore habitats (sensu Beck et al., 2001). The nursery-reef transition zone, therefore, provides an important ecological corridor that needs further attention in spatial conservation planning, and the established framework for assessing nursery productivity may prove valuable for future reserve assessment (Nagelkerken et al., 2012; Olds et al., 2012a). The value of mangrove-reef connectivity is particularly well understood for reef fish assemblages in the Caribbean Sea and western Indian Ocean (reviewed by Grober-Dunsmore et al., 2009; Bostrom et al., 2011; Berkström et al., 2012). Interestingly, our results suggest that connectivity between Pacific mangroves and reefs affects reef fish from the same families and functional groups, over similar scales (i.e. 100s of metres), to those in the tropical Caribbean and Indian Ocean (e.g. Bostrom et al., 2011; Berkström et al., 2012). Links with neighbouring seagrass also influence the composition of fish assemblages in back-reef seascapes from each region (e.g. Olds et al., 2012b). We suggest, therefore, that seascape connectivity is likely to enhance the effectiveness of marine reserves in similar heterogeneous tropical seascapes elsewhere (sensu Nagelkerken et al., 2012). It is also important to emphasise that the effects of connectivity on reserves appeared to hold across a range of latitudes, from the highly diverse 
tropical Coral Triangle to marginal reef seascapes at the limits of their subtropical distribution. We therefore recommend that heterogeneous landscapes with high habitat connectivity should be viewed as priorities for the conservation of exploited consumers and the maintenance of ecological processes. The specific approach for evaluating and incorporating habitat connectivity into spatial conservation planning will, however, vary out of necessity with the mobility of organisms and the spatial heterogeneity of the ecosystem of interest.

Our findings demonstrate positive effects of habitat connectivity on the effectiveness of reserves across the western Pacific Ocean. We show that connected reefs and mangroves in reserves support greater fish abundance and species richness then similar fished seascapes. Our results indicate that greater effects of mangrove-reef connectivity might be expected for reserves in heterogeneous inshore seascapes, whereas inter-reef connectivity is likely to be more important to the effectiveness of reserves on offshore reefs. We suggest that by explicitly incorporating connectivity into conservation planning we may have better success in preserving biodiversity and maintaining healthy, functioning ecosystems.

\section{ACKNOWLEDGEMENTS}

We thank N. Billett, H. Faddy, P. Gartrell, M. Jimuru, T. Lavery, B. Moore, M. Olds and E. Stone for field assistance, staff at the Zela Field Research Station (UCSB), Nusa Tupe Research Station (Worldfish Centre), and Orpheus Island Research Station (JCU) for invaluable field support and S. Aswani, N. Tooler and the Roviana Conservation Foundation for help with logistics in Roviana Lagoon. We are grateful to J. Mackenzie, C. Roelfsema, the Queensland Department of Environment and Resource Management, Great Barrier Reef Marine Park Authority and Roviana Conservation Foundation for providing GIS layers for marine reserves and habitats. We thank $\mathrm{H}$. Faddy and $\mathrm{C}$. Huijbers for comments on the manuscript. Financial support was provided by the Australian Research Council (LP0989796 to RMC \& KAP), Australian Coral Reef Society and the Pacific Adaptation Strategy Assistance Program in the Australian Department of Climate Change and Energy Efficiency. 


\section{REFERENCES}

Aswani, S., Albert, S., Sabetian, A. \& Furusawa, T. (2007) Customary management as precautionary and adaptive principles for protecting coral reefs in Oceania. Coral Reefs, 26, 1009-1021.

Aswani, S. \& Hamilton, R. J. (2004) Integrating indigenous ecological knowledge and customary sea tenure with marine and social science for conservation of bumphead parrotfish (Bolbometopon muricatum) in the Roviana Lagoon, Solomon Islands. Environmental Conservation, 31, 69-83.

Baker, R. \& Sheaves, M. (2005) Redefining the piscivore assemblage of shallow estuarine nursery habitats. Marine Ecology Progress Series, 291, 197-213.

Barnes, L., Bellwood, D. R., Sheaves, M. \& Tanner, J. K. (2012) The use of clear-water non-estuarine mangroves by reef fishes on the Great Barrier Reef. Marine Biology, 159, 211-220.

Beck, M. W., Heck Jr, K. L., Able, K. W., Childers, D. L., Eggleston, D. B., Gillanders, B. M., Halpern, B., Hays, C. G., Hoshino, K., Minello, T. J., Orth, R. J., Sheridan, P. F. \& Weinstein, M. P. (2001) The identification, conservation, and management of estuarine and marine nurseries for fish and invertebrates. Bioscience, 51, 633-641.

Beger, M., Grantham, H. S., Pressey, R. L., Wilson, K. A., Peterson, E. L., Dorfman, D., Mumby, P. J., Lourival, R., Brumbaugh, D. R. \& Possingham, H. P. (2010a) Conservation planning for connectivity across marine, freshwater, and terrestrial realms. Biological Conservation, 143, 565-575.

Beger, M., Linke, S., Watts, M., Game, E., Treml, E., Ball, I. \& Possingham, H. P. (2010b) Incorporating asymmetric connectivity into spatial decision making for conservation. Conservation Letters, 3, 359-368.

Berkström, C., Gullström, M., Lindborg, R., Mwandya, A. W., Yahya, S. A., Kautsky, N. \& Nyström, M. (2012) Exploring 'knowns' and 'unknowns' in tropical seascape connectivity: a review with insights from east African coral reefs. Estuarine, Coastal and Shelf Science, 107, 1-21.

Bostrom, C., Pittman, S. J., Simenstad, C. \& Kneib, R. T. (2011) Seascape ecology of coastal biogenic habitats: advances, gaps, and challenges. Marine Ecology Progress Series, 427, 191-217.

Calabrese, J. M. \& Fagan, W. F. (2004) A comparison-shopper's guide to connectivity metrics. Frontiers in Ecology and the Environment, 2, 529536.

Choat, J. H., Clements, K. D. \& Robbins, W. D. (2002) The trophic status of herbivorous fishes on coral reefs 1: Dietary analyses. Marine Biology, 140, 613-623.

Cumming, G. S. (2011) Spatial resilience: integrating landscape ecology, resilience, and sustainability. Landscape Ecology, 26, 899-909. 
Edgar, G. J., Banks, S. A., Bessudo, S., Cortes, J., Guzman, H. M., Henderson, S., Martinez, C., Rivera, F., Soler, G., Ruiz, D. \& Zapata, F. A. (2011) Variation in reef fish and invertebrate communities with level of protection from fishing across the eastern tropical Pacific seascape. Global Ecology and Biogeography, 20, 730-743.

Estes, J. A., Terborgh, J., Brashares, J. S., Power, M. E., Berger, J., Bond, W. J., Carpenter, S. R., Essington, T. E., Holt, R. D., Jackson, J. B. C., Marquis, R. J., Oksanen, L., Oksanen, T., Paine, R. T., Pikitch, E. K., Ripple, W. J., Sandin, S. A., Scheffer, M., Schoener, T. W., Shurin, J. B., Sinclair, A. R. E., Soule, M. E., Virtanen, R. \& Wardle, D. A. (2011) Trophic downgrading of planet earth. Science, 333, 301-306.

Foley, M. M., Halpern, B. S., Micheli, F., Armsby, M. H., Caldwell, M. R., Crain, C. M., Prahler, E., Rohr, N., Sivas, D., Beck, M. W., Carr, M. H., Crowder, L. B., Duffy, J. E., Hacker, S. D., Mcleod, K. L., Palumbi, S. R., Peterson, C. H., Regan, H. M., Ruckelshaus, M. H., Sandifer, P. A. \& Steneck, R. S. (2010) Guiding ecological principles for marine spatial planning. Marine Policy, 34, 955-966.

Fox, R. J. \& Bellwood, D. R. (2011) Unconstrained by the clock? Plasticity of diel activity rhythm in a tropical reef fish, Siganus lineatus Functional Ecology, 25, 1096-1105.

Game, E. T., Watts, M. E., Wooldridge, S. \& Possingham, H. P. (2008) Planning for persistence in marine reserves: a question of catastrophic importance. Ecological Applications, 18, 670-680.

Grober-Dunsmore, R., Pittman, S. J., Caldow, C., Kendall, M. S. \& Frazer, T. K. (2009) A landscape ecology approach for the study of ecological connectivity across tropical marine seascapes. Ecological Connectivity Among Tropical Coastal Ecosystems (ed. by I. Nagelkerken), pp 493530. Springer, Heidelberg.

Harrison, H. B., Williamson, D. H., Evans, R. D., Almany, G. R., Thorrold, S. R., Russ, G. R., Feldheim, K. A., Herwerden, L. V., Planes, S., Srinivasan, M., Berumen, M. L. \& Jones, G. P. (2012) Larval export from marine reserves and the recruitment benefit for fish and fisheries. Current Biology, 22, 1023-1028.

Heck, K. L., Jr., Carruthers, T. J. B., Duarte, C. M., Hughes, A. R., Kendrick, G., Orth, R. J. \& Williams, S. W. (2008) Trophic transfers from seagrass meadows subsidize diverse marine and terrestrial consumers. Ecosystems, 11, 1198-1210.

Hodgson, J. A., Thomas, C. D., Wintle, B. A. \& Moilanen, A. (2009) Climate change, connectivity and conservation decision making: back to basics. Journal of Applied Ecology, 46, 964-969.

Hughes, T. P., Graham, N. A. J., Jackson, J. B. C., Mumby, P. J. \& Steneck, R. S. (2010) Rising to the challenge of sustaining coral reef resilience. Trends in Ecology \& Evolution, 25, 633-642. 
Kellner, J. B. \& Hastings, A. (2009) A reserve paradox: introduced heterogeneity may increase regional invasibility. Conservation Letters, 2, 115-122.

Lester, S. E., Halpern, B. S., Grorud-Colvert, K., Lubchenco, J., Ruttenberg, B. I., Gaines, S. D., Airamé, S. \& Warner, R. R. (2009) Biological effects within no-take marine reserves: a global synthesis. Marine Ecology Progress Series, 384, 33-46.

Lindenmayer, D., Hobbs, R. J., Montague-Drake, R., Alexandra, J., Bennett, A., Burgman, M., Cale, P., Calhoun, A., Cramer, V., Driscoll, D., Fahrig, L., Fischer, J., Franklin, J., Haila, Y., Hunter, M., Gibbons, P., Lake, S., Luck, G., Macgregor, C., Mcintyre, S., Macnally, R., Manning, A., Miller, J., Mooney, H., Noss, R., Possingham, H., Saunders, D., Schmiegelow, F., Scott, M., Simberloff, D., Sisk, T., Tabor, G., Walker, B., Wiens, J., Woinarski, J. \& Zavaleta, E. (2008) A checklist for ecological management of landscapes for conservation. Ecology Letters, 11, 7891.

Lindenmayer, D. B. \& Fischer, J. (2007) Tackling the habitat fragmentation panchreston. Trends in Ecology \& Evolution, 22, 127-132.

Lybolt, M., Neil, D., Zhao, J., Feng, Y., Yu, K. \& Pandolfi, J. (2011) Instability in a marginal coral reef: the shift from natural variability to a humandominated seascape. Frontiers in Ecology and the Environment, 9, 154-160.

Massol, F., Gravel, D., Mouquet, N., Cadotte, M. W., Fukami, T. \& Leibold, M. A. (2011) Linking community and ecosystem dynamics through spatial ecology. Ecology Letters, 14, 313-323.

McCook, L., Ayling, T., Cappo, M., Choat, J. H., Evans, R. D., Freitas, D. M. D., Heupel, M., Hughes, T. P., Jones, G. P., Mapstone, B., Marsh, H., Mills, M., Molloy, F., Pitcher, R., Pressey, R. L., Russ, G. R., Sutton, S., Sweatman, H., Tobin, R., Wachenfeld, D. R. \& Williamson, D. H. (2010) Adaptive management of the Great Barrier Reef: a globally significant demonstration of the benefits of networks of marine reserves. Proceedings of the National Academy of Science, USA, 107, 1827918285.

McCook, L. J., Almany, G. R., Berumen, M. L., Day, J. C., Green, A. L., Jones, G. P., Leis, J. M., Planes, S., Russ, G. R., Sale, P. F. \& Thorrold, S. R. (2009) Management under uncertainty: guide-lines for incorporating connectivity into the protection of coral reefs. Coral Reefs, 28, 353-366.

Mellin, C., Bradshaw, C. J. A., Meekan, M. G. \& Caley, M. J. (2010) Environmental and spatial predictors of species richness and abundance in coral reef fishes. Global Ecology and Biogeography, 19, 212-222.

Meynecke, J. O., Poole, G. C., Werry, J. \& Lee, S. Y. (2008) Use of PIT tag and underwater video recording in assessing estuarine fish movement 
in a high intertidal mangrove and salt marsh creek. Estuarine, Coastal and Shelf Science, 79, 168-178.

Micheli, F. \& Halpern, B. S. (2005) Low functional redundancy in coastal marine assemblages. Ecology Letters, 8, 391-400.

Mumby, P. J. (2006) Connectivity of reef fish between mangroves and coral reefs: algorithms for the design of marine resreves at seascape scales. Biological Conservation, 128, 215-222.

Mumby, P. J., Edwards, A. J., Arias-Gonzalez, J. E., Lindeman, K. C., Blackwell, P. G., Gall, A., Gorczynska, M. I., Harborne, A. R., Perscod, C. L., Renken, H., Wabnitz, C. C. C. \& Llewellyn, G. (2004) Mangroves enhance the biomass of coral reef fish communities in the Caribbean. Nature, 427, 533-536.

Mumby, P. J. \& Hastings, A. (2008) The impact of ecosystem connectivity on coral reef resilience. Journal of Applied Ecology, 45, 854-862.

Nagelkerken, I. (2009) Ecological Connectivity Among Tropical Coastal Ecosystems, Springer, Heidelberg.

Nagelkerken, I., Grol, M. G. G. \& Mumby, P. J. (2012) Effects of marine reserves versus nursery habitat availability on structure of reef fish communities. PLOS ONE, 7, e36906 doi:10.1371/journal.pone.0036906.

Nyström, M. \& Folke, C. (2001) Spatial resilience of coral reefs. Ecosystems, 4, 406-417.

Olds, A. D., Connolly, R. M., Pitt, K. A. \& Maxwell, P. S. (2012a) Habitat connectivity improves reserve performance. Conservation Letters, 5, 56-63.

Olds, A. D., Connolly, R. M., Pitt, K. A. \& Maxwell, P. S. (2012b) Primacy of seascape connectivity effects in structuring reef fish assemblages. Marine Ecology Progress Series, 462, 191-203.

Olds, A. D., Pitt, K. A., Maxwell, P. S. \& Connolly, R. M. (2012c) Synergistic effects of reserves and connectivity on ecological resilience. Journal of Applied Ecology, doi: 10.1111/1365-2664.12002.

Polis, G. A., Anderson, W. B. \& Holt, R. D. (1997) Toward an integration of landscape and food web ecology: the dynamics of spatially subsidized food webs. Annual Review of Ecology and Evolutionary Systematics, 28, 289-316.

Rees, A. J. J., Yearsley, G. K., Gowlett-Holmes, K. \& Pogonoski, J. (2012) Codes for Australian Aquatic Biota. Available from http://www.marine.csiro.au/caab/. Accessed 10 April 2012.

Sheaves, M. (2009) Consequences of ecological connectivity: the coastal ecosystem mosaic. Marine Ecology Progress Series, 391, 107-115.

Sheaves, M. J. (1993) Patterns of movement of some fishes within an estuary in tropical Australia. Marine \& Freshwater Research, 44, 867-880. 
Underwood, A. J. (1992) Beyond BACl: the detection of environmental impacts on populations in the real, but variable, world. Journal of Experimental Marine Biology and Ecology, 161, 145-178.

Veron, J. E. N., Devantier, L. M., Turak, E., Green, A. L., Kininmonth, S., Stafford-Smith, M. \& Peterson, N. (2009) Delineating the coral triangle. Galaxea, 11, 91-100.

Williamson, D. H., Russ, G. R. \& Ayling, A. M. (2004) No-take marine reserves increase abundance and biomass of reef fish on inshore fringing reefs of the Great Barrier Reef. Environmental Conservation, 31, 149-159.

Zeller, D., Stoute, S. L. \& Russ, G. R. (2003) Movements of reef fishes across marine reserve boundaries: effects of manipulating a density gradient. Marine Ecology Progress Series, 254, 269-280. 


\section{SUPPLEMENTARY MATERIAL}

Additional Supporting Information may be found in the online version of this article:

Appendix S1 Testing potential alternative explanations

Appendix S2 Connectivity and reserve effects on fish assemblages

Appendix S3 Connectivity and reserve effects on fish abundance

Appendix S4 Spatial variation in magnitude of reserve-connectivity effects

As a service to our authors and readers, this journal provides supporting information supplied by the authors. Such materials are peer-reviewed and may be reorganized for online delivery, but are not copy-edited or typeset. Technical support issues arising from supporting information (other than missing files) should be addressed to the authors.

\section{BIOSKETCH}

Andrew Olds is a research fellow at Griffith University and the Australian Rivers Institute - Coast and Estuaries (Gold Coast, Australia). His research focuses on community ecology, biogeography and the impacts of global change on marine ecosystems.

The research team includes ecologists from universities and research organizations in Australia and Solomon Islands who are examining effects of marine reserves on ecological processes, ecosystem services and socioecological resilience. A.O., K.P. and R.C. conceived and designed the study; A.O., P.M. and S.A. collected the data; A.O. led the data analysis and writing; all authors contributed to interpreting the results and developing the manuscript. 